\title{
THE TOLERANCE OF SOME BREAD WHEATS, DURUM WHEATS AND TRITICALES TO HERBICIDES USED FOR WILD OAT CONTROL
}

\author{
W.J.P. MITCHEL \\ Crop Research Division, DSIR, Private Bag, Palmerston North \\ SUMMARY \\ A field trial of two bread wheat cultivars, two durum wheat cultivars \\ and two triticale cultivars was sprayed with three herbicides \\ recommended for wild oad (Avena fatua) control at the recommended \\ rate and double rate. Plant heights were reduced and maturity delayed by \\ difenzoquat and flamprop-methyl at both rates and by dichlofop-methyl \\ at the high rate. Grain yields were reduced by difenzoquat and dichlofop- \\ methyl at the high rate and by flamprop-methyl at both rates. There were \\ significant differences between cultivars and their reaction to some \\ chemicals, but neither durum wheat showed adverse effects from \\ chemicals.
}

\section{INTRODUCTION}

The effect of chemicals sprayed over bread wheat crops for the control of wild oats has been reported (Mitchel 1981). The effect of difenzoquat on one cultivar of a bread wheat, a durum wheat and a triticale has also been reported (Anon 1979). Durum wheats are under evaluation for commercial production in South Canterbury, while triticale cultivars are being tested in a number of districts for production of feed grain or for milling into speciality four blends. As wild oats can substantially reduce yields of all cereal crops, some knowledge of the tolerance of these new cereal crops to chemicals used for wild oat control was considered desirable.

\section{MATERIALS AND METHODS}

A replicated trial of Karamu and Oroua bread wheats, Vernum and Vernum $x$ Crane selection durums and Beagle and Mapache triticales was sprayed with three herbicides (see Tables), at the recommended and at double the recommended rate. The trial was a four-replicate split-plot design with chemicals as main plots and cultivars as sub-plots. The trial was sown on 9.10 .81 using a cone seeder, with plots of 3 rows at 15 $\mathrm{cm}$ coulter spacing and $5.5 \mathrm{~m}$ long. Chemicals were applied when the crop was at the 6 leaf stage with a propane-operated sprayed using 730154 Teejets giving an application rate of 240 litres/ha. Dichlorprop + MCPA + dicamba $(1.8+0.5+0.56 \mathrm{~kg} / \mathrm{ha}) \mathrm{had}$ been applied 10 days before to control broad-leaf weeds.

Plant damage caused by the sprays was recorded 4 weeks after spraying, and information on differences in relative maturity (days from sowing to $50 \%$ ear emergence), plant heights at harvest, and grain yields was obtained.

\section{RESULTS AND DISCUSSIONS}

Oroua showed moderate and all other cultivars slight phytotoxicity symptoms after spraying with difenzoquat at the high rate.

Plant height at harvest was significantly reduced by all chemicals except diclofopmethyl (Table 1). There were significant interactions between cultivars and chemicals. Oroua and Mapache were more sensitive than the other cultivars to difenzoquat at the high rate and to flamprop-methyl at both rates. In both cultivars the height reduction from these sprays was approximately $10 \mathrm{~cm}$, whereas the average reduction for the other cultivars was approximately $5 \mathrm{~cm}$.

Proc. 35th N.Z. Weed and Pest Control Conf. 
TABLE 1: Main effects of chemicals on cultivars.

\begin{tabular}{lrrr}
\hline Herbicides (kg/ha) & $\begin{array}{c}\text { Height } \\
(\mathrm{cm})\end{array}$ & $\begin{array}{c}\text { Ear } \\
\text { emergence } \\
\text { (days) }\end{array}$ & $\begin{array}{r}\text { Yield relative } \\
\text { to untreated }\end{array}$ \\
\hline untreated & 89.4 & 67 & 100 \\
difenzoquat 1.0 & 84.6 & 69 & $(5.85 \mathrm{t} / \mathrm{ha})$ \\
difenzoquat 2.0 & 82.7 & 70 & 99 \\
diclofop-methyl 1.0 & 87.3 & 67 & 93 \\
diclofop-methyl 2.0 & 86.3 & 68 & 105 \\
flamprop-methyl 0.75 & 83.5 & 68 & 96 \\
flamprop-methyl 1.5 & 82.3 & 68 & 91 \\
LSD 1\%0 & 3.9 & 1 & 80 \\
Cultivars: & & & 8 \\
Karamu & 76.8 & 68 & 100 \\
Oroua & 79.3 & 71 & 97 \\
Vernum & 77.3 & 68 & 101 \\
Vernum x Crane & 72.7 & 67 & 79 \\
Beagle & 108.8 & 68 & 111 \\
Mapache & 96.1 & 66 & 95 \\
LSD 1\% & 2.9 & 1 & 5 \\
& & & \\
\hline
\end{tabular}

Ear emergence was delayed on average by 2.5 days by difenzoquat (Table 1). Oroua was the only cultivar to show a significant interaction to chemicals. When sprayed with difenzoquat maturity was delayed by 13 days at the low rate and 16 days at the high rate.

Grain yields were reduced by difenzoquat at the high rate and by flamprop-methyl at both rates (Table 1). There were significant interactions between chemcials and cultivars (Table 2). Oroua was depressed in yield by application of difenzoquat at the high rate and Mapache at the high rate of flamprop-methyl. Other cultivars showed yield reductions after treatment but the results did not reach significance due to high experimental variation. Mapache and the Vernum $x$ Crane durum showed apparent positive yield responses to chemicals in some comparisons but further experimentation would be required to confirm these observations.

Previous work showed that Karamu wheat appeared unaffected by herbicides used for wild oat control, but Oroua wheat suffered from reduced plant height, delayed maturity and yield loss when sprayed with difenzoquat at double rate (Mitchel 1981).

Neither of the durum or triticale cultivar tested show specific susceptibility to the herbicides used and this would not be a factor to limit their commercial production.

TABLE 2: Chemical $x$ cultivar interaction. Yield relative to untreated yield $=100$

\begin{tabular}{lrrrrrr}
\hline $\begin{array}{l}\text { Treatment } \\
\text { (kg/ha) }\end{array}$ & Karamu & Oroua & Vernum & $\begin{array}{l}\text { Vernum } \\
\text { x Crane }\end{array}$ & Beagle & Mapache \\
\hline untreated & 100 & 100 & 100 & 100 & 100 & 100 \\
difenzoquat 1.0 & 91 & 88 & 96 & 114 & 102 & 109 \\
difenzoquat 2.0 & 92 & 78 & 87 & 109 & 98 & 101 \\
diclofop-methyl 1.0 & 96 & 96 & 87 & 124 & 97 & 118 \\
diclofop-methyl 2.0 & 90 & 92 & 99 & 104 & 97 & 104 \\
flamprop-methyl 0.75 & 92 & 96 & 92 & 96 & 85 & 84 \\
flamprop-methyl 1.5 & 92 & 97 & 95 & 91 & 91 & 74 \\
LSD 5\% & 16 & 17 & 16 & 23 & 15 & 18
\end{tabular}




\section{ACKNOWLEDGEMENTS}

The author wishes to thank the staff of the CRD substation, Palmerston North for assistance with conducting the trial.

\section{REFERENCES}

Anonymous, 1979. International Maize and Wheat Improvement Centre. CIMMYT Report on Wheat Improvement 1979. El Batan, Mexico. pp. 104-109.

Mitchel, W.J.P., 1981. Tolerance of spring wheat cultivars to herbicides used for wild oat control. Proc. 24th N.Z. Weed and Pest Control Conf.: 186-188. 